\title{
Building capacity through urban agriculture: report on the askîy project
}

\author{
Wanda Martin, PhD, RN; Lindsey Vold, BSN, RN
}

This original qualitative research article has been peer reviewed.

Tweet this article

\begin{abstract}
Introduction: Many North American cities have a built environment that provides access to energy-dense food and little opportunity for active living. Urban agriculture contributes to a positive environment involving food plant cultivation that includes processing, storing, distributing and composting. It is a means to increase local food production and thereby improve community health. The purpose of this study was to understand how participating in urban agriculture can help to empower young adults and build capacity for growing food in the city.
\end{abstract}

Methods: This was a qualitative study of seven participants (five Indigenous and two non-Indigenous) between the ages of 19 and 29 years, engaged as interns in an urban agriculture project known as "askîy" in Saskatoon, Saskatchewan, Canada in 2015. We used a case-study design and qualitative analysis to describe the participants' experience based on the sustainable livelihoods framework.

Results: A collaborative approach had a great effect on the interns' experiences, notably the connections formed as they planned, planted, tended, harvested and sold the produce. Some of the interns changed their grocery shopping habits and began purchasing more vegetables and questioning where and how the vegetables were produced. All interns were eager to continue gardening next season, and some were planning to take their knowledge and skills back to their home reserves.

Conclusion: Urban agriculture programs build capacity by providing skills beyond growing food. Such programs can increase local food production and improve food literacy skills, social relationships, physical activity and pride in community settings.

Keywords: food security, urban agriculture, self-reliance, resilience, capacity building, social capital, social cohesion, sustainable livelihoods framework

\section{Introduction}

Urban agriculture is a community health intervention with the potential to increase local food production and to improve food literacy skills, social relationships, physical activity and pride in community settings. ${ }^{1}$ One such intervention, the askîy project, has been operating since 2014 through CHEP Good Food Inc., with partners from the Saskatoon Food Council and the University of Saskatchewan. The Mosaic Company and Indigenous and Northern Affairs Canada's Urban Partnerships Program have funded the askîy project. The project participants are young adults, identified as "interns," who plant and tend urban vegetable gardens for the summer. The interns chose the project's name, askîy, which is a Cree word for earth. The project supports personal growth and engages First Nation and non-First Nation young adults in urban agriculture, developing food-growing skills and entrepreneurial skills through selling produce at the Saskatoon Farmers’ Market.

The purpose of this present study, which was unfunded, was to understand the effects on young adults of participating in urban agriculture, and to provide pilot

\section{Highlights}

- The askîy project provided participants with opportunities for knowledge exchange on First Nations culture.

- Interns spoke of future jobs, improved communication and interpersonal skills, confidence in their bodies, setting goals, improved attitude towards food, diet changes, and valuing of nature and strong social ties.

- One of the challenges was finding space to grow with access to water and electricity.

- The program builds capacity in young adults by providing a venue to apply local First Nation knowledge, creating a safe space for mistakes, introducing new ideas, allowing for self-directed learning, and providing participants with marketable skills.

data for further studies on advancing urban agriculture and a self-sustainable food economy. The objectives were to explore how this project could strengthen skills, knowledge, and ability in young adults by growing food in the city, and to learn the meaning of urban food production to those involved. It is our hope that the results of this study will help CHEP Good Food Inc. enhance their urban agriculture work with inner city young adults and improve urban agriculture projects in Saskatoon.

\section{Defining the problem}

With an anticipated five billion people living in urban settings around the world by the year 2025, experts are questioning our ability to meet the demand for nutritious

\section{Author reference:}

College of Nursing, University of Saskatchewan, Saskatoon, Saskatchewan, Canada

Correspondence: Wanda Martin, College of Nursing, University of Saskatchewan, 104 Clinic Place, Saskatoon, SK S7N 2Z4; Tel: 306-966-5429; Fax: 306-966-6621; Email: wanda.martin@usask.ca 
food. ${ }^{2}$ Currently, in Saskatchewan, $67 \%$ of the population lives in urban areas, ${ }^{3}$ and the urban population is expected to rise with the City of Saskatoon, which is planning for a population of half a million people by $2023 .{ }^{4}$ Planning is necessary to meet the increasing demand for nutritious food. Approximately $10 \%$ of the population (36 000 people) of the Saskatoon Health region identify as Aboriginal (First Nations and Metis peoples), ${ }^{5}$ of which $70 \%$ are employed with an average annual income of $\$ 13000 .{ }^{6}$ Moreover, the core neighbourhoods in Saskatoon, such as Riversdale, are home to individuals and families of whom approximately $57 \%$ have incomes below $\$ 25000$ per year. ${ }^{7}$ Public health nutritionists in the province estimate the annual cost of a nutritious food basket (basic healthy foods to meet recommendations from Eating Well with Canada's Food Guide) in larger Saskatchewan cities to be approximately $\$ 10000$ per year, leaving little money for other living expenses for those in the lower income brackets. ${ }^{8}$ Given the anticipated growth in Saskatoon's population and the struggles lower-income households currently face, public health professionals can do more to build resilience in urban settings, particularly with the First Nation and Metis peoples population, by providing communities with tools for urban food production. This goal is in line with the City of Saskatoon's Strategic Plan 2013-2023, which speaks of the city's history of self-reliance and stewardship, and the fact that its residents "grow more food in the city." ${ }^{4, p .31}$ This is urban agriculture.

\section{Urban agriculture}

Examples of urban agriculture include tending gardens in various places throughout the city, as well as keeping micro-livestock such as hens, rabbits and bees. ${ }^{9,10}$ These activities involve civic participation in food system governance and offer an opportunity for food sovereignty within an urban setting. The food sovereignty movement recognizes political and economic power in the food system and is a critical alternative to the neoliberal model favouring market forces over health equity. ${ }^{11}$ It refers to a process of expanding democracy to regenerate local, autonomous, healthy and ecologically sound food systems that respect the rights of people to decent working conditions and incomes. ${ }^{12,13}$ Weiler and colleagues ${ }^{14}$ describe how food sovereignty and health equity share an orientation to promote human thriving by equalizing access to power and the flow of goods through the food system. Urban agriculture provides opportunities for citizens to participate directly in their food system, gain a sense of power and control, and improve health.

\section{Systems perspective}

Quality food production is only one aspect of the health benefits of urban agriculture, as there are additional paths to sustainable livelihoods that can improve health equity, such as a healthy built environment and sufficient income. ${ }^{1}$ Achieving quality food production and a healthy built environment involves a systems perspective. The concept of sustainable livelihoods has traditionally been used in rural settings and refers to different types of capital, or resources, that can aid in recovery from stresses or shocks. ${ }^{15}$ To support sustainable livelihoods, public health professionals can consider the various sectors involved with the physical, natural, human, social and financial assets outlined in the British Department for International Development's sustainable livelihoods framework. ${ }^{16}$ The World Health Organization has called for integrated policies and programs based on intersectoral collaboration that can ensure a healthy and sustainable food supply, improve social cohesion, and provide environmental and economic benefits to positively affect health equity. ${ }^{17}$ Programs that integrate these sectors and also engage the whole system will be important indicators of success in working toward improved urban health.

The sustainable livelihoods framework consists of the five assets touched on above-physical, human, social, financial and natural. Physical assets include basic infrastructure within the urban setting, including water supply, transportation and access to information. ${ }^{16}$ The physical assets in a city can help to inform the way citizens think about where they live and influence feelings of pride and selfrespect, further contributing to the overall perception of good health. Human assets include the knowledge, skills, ability to labour and good health that allow people to pursue a livelihood. ${ }^{16}$ Social assets involve networks and connectedness that foster cooperation. ${ }^{18}$ Specifically, this includes community engagement, inclusiveness and neighbourhood stewardship. ${ }^{16}$ Financial assets are the cash or equivalents that are available to adopt livelihood strategies. ${ }^{16}$ These tend to be the least available to those who have the most to gain from improving health equity. ${ }^{19}$ Natural assets in urban agriculture are those that increase exposure to outdoor physical activity (such as green space), providing major health benefits. ${ }^{20}$ Improving natural assets in the urban environment is essential for a healthy population now and in the future.

\section{The askîy project}

Working in Saskatoon's downtown core neighbourhoods, the askîy interns transformed a brownfield site* using over 300 containers for planting. The interns applied for four months of summer employment in an urban garden with the aim of developing food production skills, leadership skills and marketing skills at a local farmers' market. Faculty at the University of Saskatchewan College of Agriculture and Bioresources and staff at CHEP Good Food Inc. provided regular support and informal education through hands-on learning. Two interns had some prior knowledge of gardening, and took the lead in mentoring their peers. The interns employed a collective leadership style that encouraged group problem solving. They named the space kiscikânis ("garden" in Cree), and produced a wide variety of vegetables and herbs, flowers and traditional tobacco plants. The purpose of the project was to educate and empower community members with the necessary knowledge and skills to create a self-sustainable food economy through urban agriculture. ${ }^{21}$ The majority of the interns had no prior gardening knowledge, but successfully engaged in the project to grow and sell produce. They also shared their developing knowledge with others, including new Canadians.

\section{Method}

We chose a case-study design for this study. We used qualitative thematic analysis with multiple coders. ${ }^{22}$ A case-study design is preferred when asking "how" or "why" questions. ${ }^{23}$ This study consisted of one-time, open-ended, one-hour interviews with all seven of the interns from the intervention project. While a focus 
group would capture the dynamics of the group, individual interviews allowed participants to consider and express the meaning they made of being engaged in the summer internship program. We obtained ethical approval from the University of Saskatchewan Behavioural Research Ethics Board. The program coordinators informed the interns of the opportunity to participate, and arranged a time and place for the interviews. We emphasized the voluntary nature of the interviews, and all the interns were engaged in the process. We used pseudonyms in this report to personalize the interns' quotations.

The audio of the individual interviews was recorded and transcribed for analysis using NVivo 11 qualitative software (QSR International Pty Ltd., Melbourne, AUS). To explore the effects of participating in the intervention project, we read the transcripts and thematically categorized the data to provide an overall description of the experience of participating in the askîy project. We clustered concepts to identify themes and compared emerging themes to the sustainable livelihood framework. ${ }^{16}$

We compared the findings to the sustainable livelihood framework as a means of capturing the original purpose of the askîy project, i.e. to create a self-sustainable food economy through urban agriculture. The purpose of this study was to complement the askîy project by explaining the participant experience within urban agriculture and identifying limitations to advancing a self-sustainable food economy. The resulting findings and gaps are driving additional sampling and research projects related to the creation of self-sustainable food economies through urban agriculture.

There were originally eight interns in the askîy project, but one moved prior to our data collection. The remaining seven agreed to be interviewed. The age range of those interviewed was 19 to 29 years. Five participants were of First Nations or Métis heritage, and two identified as Caucasian. Five participants were either University of Saskatchewan students or had recently completed their educational program. Their programs of study were education, arts and science, chemical engineering and renewal resource management. Two of the participants were parents. Three participants had previous gardening experience, but none expressed confidence in their gardening abilities at the beginning of the program, identifying themselves as beginner gardeners.

\section{Results}

\section{The meaning of urban agriculture}

While not specifically part of the sustainable livelihood framework, we were interested in the meaning of urban agriculture for the interns and in the integration of First Nation knowledge into the askîy project. Participants emphasized that urban agriculture produced quality, healthy food while making use of available space. To these participants, urban agriculture was about discovery, flexibility and the creation of green space in an urban centre. One participant, Kara, considered urban agriculture beyond the physical, something contributing to their spirituality. She said:

It's like a big giant tree with all these roots, and it's all connected. That's what I'm finding about, is that we're all really so connected, and the great thing about urban agriculture is that in this modern society we can be so disconnected from our earth and to the bigger picture, and you can kind of find the middle ground with urban agriculture because you know the city makes it loud, busy, but then you can find this moment of peace, and you're like, in the garden and, I find it's very spiritual.

For Kara, the opportunity to engage with the soil and the process of growing meant more than just producing food. Gardens allowed for participation and realization of local knowledge and a reconnection to the land. ${ }^{25}$ Memory and daily acts of gardening represented a greater connection to traditional knowledge and culture. Growing vegetables acted as a catalyst in reconnecting to First Nation ancestry and the earth by growing traditional plants (e.g. tobacco) and being close to the ground, smelling the soil, and nurturing plant growth.

\section{First Nation knowledge}

The interns lead the integration of First Nation knowledge into the project. The team brought the Cree language into the project and incorporated traditional methods into kiscikânis, such as planting in a circle with four openings, one for each direction. Another participant, Tammy, explained that the openings are "so each grandfather and spirit can come in, and join the ceremony." The team invited community elders to the gardens to bless the land, and others sought First Nation knowledge and teachings from their family members and elders living on their home reserve. They also learned that it is important to have positive thoughts and positive energy when planting and to talk to the plants because every plant has a spirit. It is through that expression of love that the interns spoke of feeling more connected, more confident and happier.

Additionally, they planted some native species, and ceremonial tobacco. Tobacco is important because First Nations people use it in ceremonies as well as giving it as offerings. Ana, another intern, explained that tobacco is "used in ceremonies as well, or if you are asking an elder for knowledge or going to a medicine man, or going to a sweat, and whoever is leading the sweat you give that offering, which is usually tobacco." Being part of the askîy project, with its strong First Nations lens, provided the interns with opportunities for an exchange of knowledge that is a vital part of cultural rejuvenation. Donna noted:

I've never experienced a blessing before, so that was really great to see. We went to a powwow, I have been to a powwow before, but I've never been that involved in one before. So a lot of it is new to me, it's really interesting, I'm learning a lot.

The interns expressed that the exposure to the applied Traditional knowledge was a significant outcome of this project that all of the participants will carry with them. For some participants, the askîy project was the perfect combination of time, place, and mode to help them see the world from a First Nations perspective.

\section{Growing food — physical assets}

The main challenge in this project was finding a space to grow food safely. For example, vacant lots may be vacant because of contamination issues. The team settled on a neighbourhood brownfield because there was insufficient alternative growing space. They planted their plants in 323 plastic barrels, cut lengthwise, 
and placed on wooden pallets to avoid contaminated soil.

Water was also a significant challenge. The interns underestimated the heat retention of the plastic barrels, which required more watering than in-ground gardens, and which had to be done by hand. The unused site had no water access, so the team purchased a large water tank that members of the Saskatoon Fire Department filled voluntarily. The tank required a water pump, which in turn meant the garden needed electricity, leading to the purchase of a battery. At each challenge, the team worked to find a solution.

Access to information is also a physical asset. The team expressed that a generation gap had resulted in knowledge being lost, as described by Ana:

I didn't grow up in a family that taught me how to garden, or you know, didn't have gardens, my grandma had flower beds and stuff, but she never grew food. So, I didn't really know how to grow food.

Growing food was not common when the interns were growing up, and they did not know where to go to learn how to do it, or to get mentorship. However, they did find knowledge resources through the Internet. When asked what would be helpful to bridge the knowledge gap, James suggested developing a resource kit or workers' co-op with a focus on growing food, where people could feel comfortable accessing information and resources. Access to information, for James, was every bit as important as physical access to land and water, and adequate support for trying something new.

\section{Personal growth-human assets}

The opportunity for self-discovery can be a great asset. Many of the interns had no previous experience with gardening, or at least gardening was not common practice in their family. The participants reported increasing their knowledge of growing food, they expressed concern about where their food comes from and how it is grown, and they talked about changes in their attitudes towards food. They were beginning to value local food. This may be because the interns came to the realization that significant labour goes into growing food, or because of the taste of locally grown food and the growing community of people interested in local food in Saskatoon.

Participants commented on how the project had changed them. They spoke of future jobs, better communication skills, interpersonal skills, confidence in their bodies, setting goals, attitude towards food, diet changes and their values. Kara commented:

A few months before I got the internship I started implementing a healthier diet, I started working out a bit more, so I was a little bit more healthier when I started. And then, this just sort of snowballed when I got the job. Because obviously you're working outdoors, it's a very physical job, and then once you see that growth, you think, oh wow!

The interns' sense of pride and accomplishment came through powerfully in the interviews. Improving participants' conceptualization of health may be associated with the restorative effect of urban gardening and urban green space through increased well-balanced lifestyle choices, engaging in physical activity, and selfreported decreased mental stress. ${ }^{26}$

The personal growth experienced by participants appears to be quite emotionally compelling. Doug found the experience particularly transformative. He said:

It's pretty humbling to know that, you know, I've just started gardening when I'm 25, or 24 was when I started, and I only have a certain amount of harvests left. And I probably think my life in terms of years, but I think more so now I think in terms of harvests, and so I've probably like, if I was to garden until I was 70 say, for example, I have like 45 , or 50 more batches of my salsa.

Doug, like others in the group, has changed the way he views his life; he now thinks in terms of harvests and not in years. Learning about growing food, working out the daily logistics of gardening on a brownfield, marketing the produce, and working in a team setting offered these participants a rich experience that may affect and even shape their future.

\section{Effect on others-social assets}

The participants shared the garden experience with others in the community by way of a group serving new Canadians. This association was mutually beneficial, because the participants received help with planting and harvesting, while the new Canadians had a way to meet people and practise speaking English. Similarly, First Nation and non-First Nation participants also experienced these cross-cultural interactions. Participants experienced mutuality and trust in spite of cultural differences. Community gardening brought diverse people together.

The social interaction and exchange of ideas was a highlight for this group. Not only did they learn gardening skills and marketing skills, but also, and more importantly, they learned to work as a team and to value their different strengths. One intern commented about his previous jobs and the difference in this experience. When asked about what he would be taking away from this project, Jeff said:

Definitely the ability to work as a group. Yup, cause in most of my other jobs, it wasn't so team based. You know, you're kind of on your own, or there's someone telling you what to do. So this, it was interesting for me, cause I've never really worked in a group setting like this. Like where everyone's voice mattered, and where it was like a universal decision, instead of just one person making the decision.

We attribute some of this sense of cohesion to the leadership team. Doug noted how he has grown in his leadership style, from acting like the "boss" to working more from a positon of respect. Doug explained:

[Telling people what to do], that doesn't go over well, maybe it worked for, for another generation but I think for millennials you kind of have to, you kind of have to give respect to get it, and people need to be people.

Doug was conscious of wanting respect from the team, and that meant being the first one on site, and working hard, listening to others and showing respect for everyone's ideas and contributions. Both team leaders had the same philosophy 
and fostered an atmosphere that feeds a caring team approach.

The social assets of the askîy project are evident. Working together, being receptive to people in the neighbourhood and being open to including other groups made this experience particularly rich.

\section{The business of growing and selling food-financial assets}

Some interns noted that selling vegetables at the Saskatoon Farmers' Market was profitable, but there was no discussion about the larger costs of labour to produce the food, or costs of inputs, such as compost, water and electricity. There was no cost-benefit analysis at the time of the interviews. The interns did not measure benefits in terms of money, but in knowledge gained, which they could translate to other communities, and in the richness of their relationships with one another. The project was not self-funded, and therefore did not rely on making a profit from sales. The question remains whether urban agriculture can be a viable business for young adults who are new to this activity. The lack of discussion about the finances may have been due to a lack of education on this aspect of food production as part of the project. The value of the project to the interns at this point lay much more in gaining the knowledge to share. Tammy noted:

I wouldn't sell it for a lot. Like even, 'cause like, I'm all about taking this knowledge back home to help my community, and there's people out there who don't have tons of money, like to actually buy all this fresh produce and stuff, or even just by donation. Making this, like, I wouldn't sell it for a lot.

Jeff recognized the need for a grant for start-up costs if they were to make this a viable business, thinking that for the first three years, participants would need extra support. Ana and Donna identified how tough the food-growing business is, and even though many farmers appear happy, many are discouraged, indebted people who experience a lot of stress. The interns spent some time with a market producer and witnessed the barriers small-scale producers face beyond physically working the soil.
Future job prospects may be open to the interns, based on their unique summer experience. When asked if being involved in this project would help to get a job in the future, James said:

Probably, yeah, I would hope so, because there has only been dishwashing on my résumé. Agricultural intern on there, I think that would kind of make people want to know more about what I did here.

While the project does not support financial gain, marketable skills may be a financial asset.

\section{Working out of doors_natural assets}

Participants talked about the natural assets and expressed how good it was to be working out-of-doors. They also talked about the insects, whether pests were eating the plants, or if they were seeing beneficial insects. Ana described the increase in insects this way, as "biodiversity, so like, our garden, it's attracting a lot of butterflies and bees, which is really awesome." The interns mentioned other natural assets such as the reduction in the island heat effect, recycling of food waste into compost and potential for rainwater catchment to reduce storm water run-off.

Urban gardens serve as a collective space for transferring knowledge and cultural traditions and for producing socioecological memories of how to grow food and successfully navigate through the challenges of growing. ${ }^{27}$ Overall, urban gardens and ecosystems provide a long roster of critical services affecting socioecological health and well-being in urban centres.

\section{Discussion}

The objectives of this research were to understand how the askîy project could build capacity in young adults growing food in the city, and to explore the meaning of urban agriculture to the intern participants. The interns commented that they were proud of what they had achieved in seeing the project through to the end. They spent time learning to grow plants, feeling connected to the land, and going back to their roots while creating something green, beautiful and useful. They were doing something that could help their community; and it required physical activity in sometimes challenging conditions; but in the end, they felt empowered. These participants demonstrated that the hard work of gardening can develop life skills, and that the rewards are worth the hard work.

Learning moved beyond the urban setting. Participants that were from or had connections to reserves commented on the lack of fresh food available there due to the expense of shipping produce to remote areas. Because of their involvement with this project, they realized there was a need in their home community that they wished to address. One intern talked about having the support of the others to create a community garden at home. They also noted how a garden might be a valuable asset for isolated communities, as well as for urban dwellers without yards, low-income families or new immigrants. This is similar to what Gray and colleagues ${ }^{28}$ found in their study on the role of home gardens, in which they described how new gardeners wanted to share the beauty of producing and consuming fresh vegetables after learning about how to do it themselves.

All of the participants in the askîy project noted how gardening could lead to social change. Ana said that the urban agriculture movement is a "social movement in a positive direction." Some participants talked of gardening as a type of resistance to an industrial food system. It allowed for examination and critical reflection of the mainstream food system. This is not a new finding, but consistent with Hansen ${ }^{29}$ who discusses how community gardens can be a site of resistance to the global food system. This practice of local food sovereignty gives people a sense of power and control, and the notion of ownership in a democratic space where people share social, environmental and economic goals. ${ }^{29}$ Gardens can be a focal point for community members to come together recognizing what they can accomplish with collective power. ${ }^{30}$ As the forces of globalization and an increasingly individualized society press down upon us, communities and communal gardening can be a source of identity and social cohesion. As an area for recreation, the community garden becomes an extension of social processes that contribute to identity in terms of where we live. ${ }^{31}$

Although we did not use an Indigenous approach to guide our study, the application 
to the program reflects the values of the interns and their capacity to bring First Nation knowledge into their summer internship. The askîy project helped to build capacity in young adults by creating an opportunity to apply and share First Nation knowledge, creating a safe space for mistakes, introducing them to new ideas, providing the opportunity for selfdirected learning and teaching them marketable skills. This particular approach to an urban agriculture project is very important to its overall success and sustainability. The home gardening program described by Gray and colleagues ${ }^{28}$, for example, flourished when they employed an asset-based approach. When the organization running the program switched toward participatory development, more gardeners took ownership and worked to solve local problems while developing local leadership. The askîy project exemplifies an asset-based community development approach. For example, CHEP Good Food Inc. does not measure the outcome in kilograms of produce, but in the sharing and relationships that will remain with the interns over their lifetime.

Urban green and garden spaces are physical assets and can improve urban sustainability providing healthy infrastructure and food to citizens locally, thereby decreasing the reliance on externally produced services and the city's ecological footprint. ${ }^{32}$ We view urban gardens as an integral part of city infrastructure. Urban gardens are a community asset, especially for those living in apartments or without space for a garden, providing a better quality of life. Practising gardening within city limits promotes open green spaces, encourages biodiversity, and builds communities. ${ }^{33}$

Vulnerabilities in the project do exist and are primarily economic. This is not only because they are not themselves financially sustainable, but also from a program-learning perspective, it does not teach economic management skills. In the future, the program designers could provide interns with information on the business of urban agriculture such as calculating start-up costs, maintaining a business and employing staff. Urban gardens may also be vulnerable to changes to zoning laws for land use or change in land title for development of other resources, extreme weather events, or political change. Social, human and physical resilience developed through urban agriculture demonstrate great potential for future research. Nevertheless, the social, human and physical resilience developed through urban agriculture has been clearly demonstrated, and these vulnerabilities present opportunities for improving such programs in the future.

\section{Strengths and limitations}

This study highlights the assets of an inner-city community with a focus on engaging youth and providing a venue for their voices. Further evaluation research can build on this work to strengthen and expand the askîy project. There are study limitations, however. The descriptive design provides a snapshot of what this project is about, but a phenomenological study could provide greater detail about the lived experience of interns working and learning together. The small group was very positive and there was critical information in the interviews. A critical perspective can help to identify areas of growth and improvement. We chose the Sustainable Livelihoods Framework after the interviews, so open-ended questions were not providing the depth of detail that more directed questions would solicit to address the framework fully. The study, however, did capture the meaning of the project, and helped to demonstrate to the interns the value of asset-based community development.

\section{Conclusion}

The main strengths of the project lie in its human and social assets, but all sustainable livelihood assets apply. The people who were part of this project in 2015 demonstrated great potential to take what they learned working with CHEP Good Food Inc. to share with their networks. Building local resilience and developing self-reliance are part of a vision for a better future. Creating community food systems helps people not only to produce food, but also to reconnect with nature and with their culture. The next step of this research will be to develop outcome indicators to measure the effects of similar gardening programs-indicators that reflect not only the outputs of gardening, but also social capital, knowledge translation and exchange, and personal empowerment.

\section{Acknowledgements}

We would like to thank staff members at CHEP Good Food Inc. and Grant Wood from the College of Agriculture and Bioresources at the University of Saskatchewan for facilitating this project.

\section{Conflicts of interest}

The authors have no conflicts of interest to declare.

\section{Authors' contributions and statement}

WM designed the study and interpreted the data. Both authors contributed to the writing and the critical review of the manuscript, and have read and approved the final version.

The content and views expressed in this article are those of the authors and do not necessarily reflect those of the Government of Canada.

\section{References}

1. Lovell R, Husk K, Bethel A, Garside $\mathrm{R}$. What are the health and well-being impacts of community gardening for adults and children: a mixed method systematic review protocol. Environ Evid [Internet]. 2014 [cited September 14, 2017];3(1):20. Available from: https://environmentalevidencejournal .biomedcentral.com/articles/10.1186 /2047-2382-3-20

2. MacRae R, Gallant E, Patel S, Michalak M, Bunch M, Schaffner S. Could Toronto provide $10 \%$ of its fresh vegetable requirements from within its own boundaries? Matching consumption requirements with growing spaces. J Agric Food Syst Community Dev. 2010;1(2): 105-27.

3. Statistics Canada. Canadian megatrends: Canada goes urban [Internet]. Ottawa (ON): Statistics Canada. 2015 Nov 11 [modified 2017 Mar 3; cited 2015 Nov 11]. Available from: http:// www.statcan.gc.ca/pub/11-630-x/11 -630-x2015004-eng.htm

4. City of Saskatoon. Strategic plan 2013-2023. Saskatoon (SK): City of Saskatoon; 2013.

5. First Nations and Métis Population. Community view collaboration 2014 [cited 2016 May 5]. Available from: http://www.communityview.ca/pdfs /2014_SHR_FirstNations_Metis.pdf 
6. Gendron F, Hancherow A, Norton A. Exploring and revitalizing Indigenous food networks in Saskatchewan, Canada, as a way to improve food security. Health Promot Int. 2017; 32(5):1-10. doi: 10.1093/heapro/daw013.

7. City of Saskatoon. Neighbourhood profiles: Riversdale [Internet]. Saskatoon (SK): City of Saskatoon. 2015 [cited 2016 Apr 28]. Available from: https:// www.saskatoon.ca/sites/default /files/documents/community-services /planning-development/research /neighbourhood-profiles/riversdale .pdf

8. Saskatchewan Food Costing Task (SFCT) Group. The cost of healthy eating in Saskatchewan 2012. Saskatoon (SK): SFCT Group; 2012. 24 p.

9. La Rosa D, Barbarossa L, Privitera R, Martinico F. Agriculture and the city: a method for sustainable planning of new forms of agriculture in urban contexts. Land Use Policy. 2014;41: 290-303.

10. Smit J, Nasr J. Urban agriculture for sustainable cities: using wastes and idle land and water bodies as resources. Env Urbanization. 1992; 4(2):141-52.

11. Wittman H, Desmarais AA, Wiebe N, editors. Food sovereignty in Canada. Halifax (NS): Fernwood Publishing; 2011. 232 p.

12. Blouin, C, Lemay J-F, Ashraf K, Imai J, Konforti L. Local food systems and public policy: a review of the literature [Internet]. Montréal (QC): Équiterre and The Centre for Trade Policy and Law; 2009 [cited September 14, 2017]. Available from: https://foodsecure canada.org/sites/foodsecurecanada .org/files/localfoodsystemsandpublic policy_sept2009_0.pdf

13. Pimbert M. Towards food sovereignty: reclaiming autonomous food systems. [Internet].London (UK): The International Institute for Environment and Development; 2009 [cited September 14, 2017]. Available from: https://www.iied.org/towards-food -sovereignty-reclaiming-autonomous -food-systems
14. Weiler AM, Hergesheimer C, Brisbois B, Wittman H, Yassi A, Spiegel JM. Food sovereignty, food security and health equity: a meta-narrative mapping exercise. Health Policy Plan. 2015;30(8):1078-92.

15. Scoones, I., Livelihoods perspectives and rural development. J Peasant Stud. 2009;36(1):171-96.

16. Department for International Development (DFID). Sustainable livelihoods guidance sheets. London (UK): DFID; 1999. $150 \mathrm{p}$.

17. de Leeuw E, Tsouros AG, Dyakova M, Green G. Healthy cities: promoting health and equity-evidence for local policy and practice. Copenhagen (DK): World Health Organization; 2014. 32 p.

18. Morse S, McNamara N. The theory behind the sustainable livelihood approach. In: Morse S, McNamara N, editors. Sustainable livelihood approach: a critique of theory and practice. London (UK): Springer Science and Business Media; 2013:15-60.

19. Marmot M, Friel S, Bell R, Houweling TA, Taylor S, Commission on Social Determinants of Health. Closing the gap in a generation: health equity through action on the social determinants of health. Lancet. 2008; 372(9650):1661-69.

20. Leake, J.R., A. Adam-Bradford, and J.E. Rigby, Health benefits of 'grow your own' food in urban areas: implications for contaminated land risk assessment and risk management? Env Health. 2009;8(Suppl 1)S6. doi: 10.1186/1476-069X-8-S1-S6.

21. Severight-Dumais K. Urban agriculture: the askîy project [Internet]. 2015 [cited 2016 April 20]. Available from: http://www.chep.org/en/programs /urbanag

22. Patton MQ. Qualitative research and evaluation methods, 2nd ed. Thousand Oaks (CA): Sage Publications, Inc.; 1990, 532

23. Yin RK. Case study research: design and methods. Beverly Hills (CA): Sage; 1984.

24. Greenberg, M., Should Housing Be Built on Former Brownfield Sites? American Journal of Public Health, 2002. 92(5): p. 703-705.
25. Beilin R, Wilkinson C. Introduction: governing for urban resilience. Urban Studies. 2015;52(7):1205-17.

26. Kabisch NS, Qureshi S, Haase D. Human-environment interactions in urban green spaces-a systematic review of contemporary issues and prospects for future research. Env Impact Assess Rev. 2015;50(Jan): 25-34.

27. Barthel S, Parker J, Ernstson H. Food and green space in cities: a resilience lens on gardens and urban environmental movements. Urban Studies. 2013;52(7):1321-38.

28. Gray L, Guzman P, Glowa KM, Drevno AG. Can home gardens scale up into movements for social change? The role of home gardens in providing food security and community change in San Jose, California. Local Env. 2014;19(2):187-203.

29. Hansen Y. Growing community: community gardens as a local practice of food sovereignty. In: Wittman $\mathrm{H}$, Desmarais AA, Wiebe $\mathrm{N}$, editors. Food sovereignty in Canada. Halifax (NS): Fernwood; 2011:151-68.

30. Gottlieb R, Joshi A. Food justice. Cambridge (MA): MIT Press; 2010. $304 \mathrm{p}$.

31. Forrest R, Kearns A. Social cohesion, social capital and the neighbourhood. Urban Studies. 2001;38(12):2125-43.

32. McPhearson T, Andersson E, Elmqvist T, Frantzeskaki N. Resilience of and through urban ecosystem services. Ecosystem Services. 2015;12(Apr): $152-6$.

33. Mougeot LJ, editor. Agropolis: The social, political and environmental dimensions of urban agriculture. London (UK): Earthscan, International Development Research Centre; 2010. $308 \mathrm{p}$. 